\title{
An Exploratory Descriptive Study: Emotional Extraction of Postpartum Women who Engaged in Horticulture Activities by Text Mining
}

\author{
Yuka Kotozaki \\ Iwate Medical University, Morioka, Japan \\ Email: y-kotozaki@umin.ac.jp
}

How to cite this paper: Kotozaki, Y. (2020). An Exploratory Descriptive Study: Emotional Extraction of Postpartum Women who Engaged in Horticulture Activities by Text Mining. Psychology, 11, 1481-1492. https://doi.org/10.4236/psych.2020.1110094

Received: September 1, 2020

Accepted: October 12, 2020

Published: October 15, 2020

Copyright $\odot 2020$ by author(s) and Scientific Research Publishing Inc. This work is licensed under the Creative Commons Attribution-NonCommercial International License (CC BY-NC 4.0). http://creativecommons.org/licenses/by-nc/4.0/

\section{(c) (i) (8) Open Access}

\begin{abstract}
The effects of horticultural activity have been studied primarily for the elderly, but few studies have been conducted for postpartum women. This study asked postpartum women to respond in an open-ended format about how the horticultural activity made them feel and used text mining to extract their feelings. The results of the co-occurrence network showed that the free descriptions before the horticultural activity were grouped into word linkages such as "horticultural activity" and "feeling of touching the soil" and "visual experience of plants". However, after the horticultural activity, the free descriptions were grouped into word linkages such as "relating to flowers" and "emotional experience through plants". As this study was exploratory and did not set a sample size, it needs to be examined with a larger sample in the future.
\end{abstract}

\section{Keywords}

Co-Occurrence Network Diagram, Emotional Changes, Free Description Type Questionnaire, Pilot Study, Positive Emotion

\section{Introduction}

Women are more susceptible to depression postpartum (Evans et al., 2001; Gavin et al., 2005; Pitt, 1968; Zaers et al., 2008). The incidence and prevalence of postpartum depression are about 10\%, respectively (Kumar \& Robson, 1984; O'Hara \& Swain, 1996; Pitt, 1968). Many women who have postpartum depression often hesitate to consult a specialist due to the difficulty of going to the hospital with an infant or having trouble with medication while breastfeeding (Bilszta et al., 2010; Kozhimannil et al., 2011). Postpartum depression, if left un- 
treated, may increase the risk of severe or chronic illness (Brennan et al., 2000; Dunkel Schetter \& Tanner, 2012) and may lead to child neglect (Friedman, 2015; Lang et al., 2006), so measures are needed to reduce the physical and psychological burden on mothers after childbirth. There are many efforts to improve postpartum depression (Horowitz \& Goodman, 2005; Kozhimannil et al., 2011; Rowan et al., 2015; Simhi et al., 2019; Zinga et al., 2005). Much of the support for postpartum mothers comes in the form of attending support events held at support centers and other agencies. If mothers themselves are reluctant to go out, or if their homes are too far away from the support center, they may feel too lazy to go out with their infants and toddlers; the support they get will not reach them if they are not willing to do so. Postpartum women with infants can feel more comfortable taking care of themselves if they have ways to take care of their moods at home right away, before their mood swings and stress levels worsen. We focused on horticultural activity as a way to care for ourselves at home.

Horticultural activity is known not only harvesting and incorporating them into life but also on the effect of the physical and psychological function (Gonzalez et al., 2010; Haller et al., 2019; Hansen-Ketchum et al., 2009; Hayashi et al., 2008; Maller et al., 2006; Page, 2008; Rappe, 2005; Sempik et al., 2003; Ulrich et al., 1991; Cimprich, 1993; Cimprich \& Ronis, 2003; Kam \& Siu, 2010; Kim et al., 2012; Park et al., 2019; Relf \& Dorn, 1995; Simon \& Straus, 1998). However, the effects of horticultural activity on postpartum women who are susceptible to significant temporary stress have not studied. This study was an exploratory study to determine what psychological changes postpartum women felt through gardening by asking them to fill out an open-ended questionnaire about how they felt through horticultural activity.

\section{Methods}

The present study was an exploratory pilot study. The Research Ethics Committee of Iwate Medical University approved all procedures. Written informed consent was obtained from all participants. The Helsinki Declaration performed all procedures.

This study recruited 15 women (mean age: $30.4 \pm 3.2$ years old) of about one year after childbirth. The women had no experience in the habitual horticultural activity. They planted and nurtured plants, weeded, and gathered the flowers they grew in their horticultural activities. This activity was guided by a facilitator with experience in horticultural activities. The women asked to fill in their free description after the horticultural activity.

Text mining was used as data analysis, and the analysis software used $\mathrm{KH}$ Coder 3 (https://khcoder.net/dl3.html). First, the components were extracted by text mining to check the frequency distribution of occurrence. The constructs were counted above the threshold of 2 (two occurrences). Next, a stratified cluster analysis was performed to attempt to organize the categories that comprise it. 
Additionally, to summarize the frequency of occurrence of extracted words and the relationship between extracted words, a co-occurrence network diagram was drawn. The co-occurrence network diagram shows the strength of co-occurrence between words with similar patterns. The circles' size indicates the frequency of the words, and the distance of the lines connecting the circles indicates the depth of the association. In the present analysis, the Jaccard coefficient was used to calculate the co-occurrence relation, which indicates the association's strength, and the analysis was conducted with the minimum number of occurrences of the extracted words as two and the number of drawings as 75 .

\section{Results}

Analysis of the frequency of occurrence of components in the free description before the horticultural activity is shown in Table 1 . The free description was a total of 58. Among the total constructs above the threshold of 2 (two occurrences) threshold, 32 words extracted from the constructs (words) characterize the tendency before the activity. The most frequent occurrence was "growing" (12 times/58, 20.7\%). Then, there were followed "flower" (8 times/58, 13.8\%), "plant" (6 times/58, 10.3\%), "enjoyment", and "increase" (5 times/58, 8.6\%). Analysis of the frequency of occurrence of components in the free description after the horticultural activity is shown in Table 2. The free description was a total of 90 . Among the total constructs above the threshold of 2 (two occurrences), 23 words were extracted from the constructs (words) that characterize the tendency after the activity. The most frequent occurrence was "flower" (10 times/90, 11.1\%). There were followed "growing" and "fun" (7 times/90, 7.8\%), "bloom" and "think" (6 times/90, 6.7\%).

Table 1. Frequency of occurrence of components before the activity.

\begin{tabular}{ll}
\hline extracted word & number of appearances \\
\hline growing & 12 \\
flower & 8 \\
plant & 6 \\
enjoyment & 5 \\
increase & 5 \\
house & 3 \\
fun & 3 \\
feeling & 3 \\
think & 3 \\
little & 3 \\
planting & 3 \\
place & 3 \\
clay & 3 \\
insecurity & 3 \\
every day & 3 \\
\hline
\end{tabular}




\section{Continued}

\begin{tabular}{ll}
\hline happy & 2 \\
teach & 2 \\
look after & 2 \\
die & 2 \\
bloom & 2 \\
hours & 2 \\
myself & 2 \\
small & 2 \\
color & 2 \\
touch & 2 \\
water & 2 \\
life & 2 \\
atmosphere & 2 \\
forget about & 2 \\
not having & 2 \\
eye & 2 \\
green & 2 \\
\hline
\end{tabular}

Table 2. Frequency of occurrence of components after the activity.

\begin{tabular}{ll}
\hline extracted word & number of appearances \\
\hline flower & 10 \\
growing & 7 \\
fun & 7 \\
bloom & 6 \\
think & 6 \\
myself & 4 \\
plant & 4 \\
child & 3 \\
childcare & 3 \\
little & 3 \\
self-possessed & 3 \\
together & 2 \\
family & 2 \\
feeling & 2 \\
trimming & 2 \\
come out & 2 \\
planted & 2 \\
worry & 2 \\
life & 2 \\
many & 2 \\
insolate & 2 \\
unpleasant & 2 \\
beautiful & \\
\hline & 2 \\
\hline
\end{tabular}


A stratified cluster analysis before the activity is shown in Figure 1. The analysis results showed that the descriptions are divided into six categories of time and plants in life: emotional experiences with plants, active involvement with plants, growing flowers, enjoyment of touching the soil, and everyday emotions. The results of the stratified cluster analysis after the activity are shown in Figure 2. The analysis revealed five categories of emotional experiences related to flowers, feeling, active engagement with plants, movements, and parenting similarities.

Figure 3 shows the co-occurrence network diagram of the first free-standing. The co-occurrence network diagram shows six subgraphs before the onset of horticultural activity. The first group includes extraction words such as "increase",

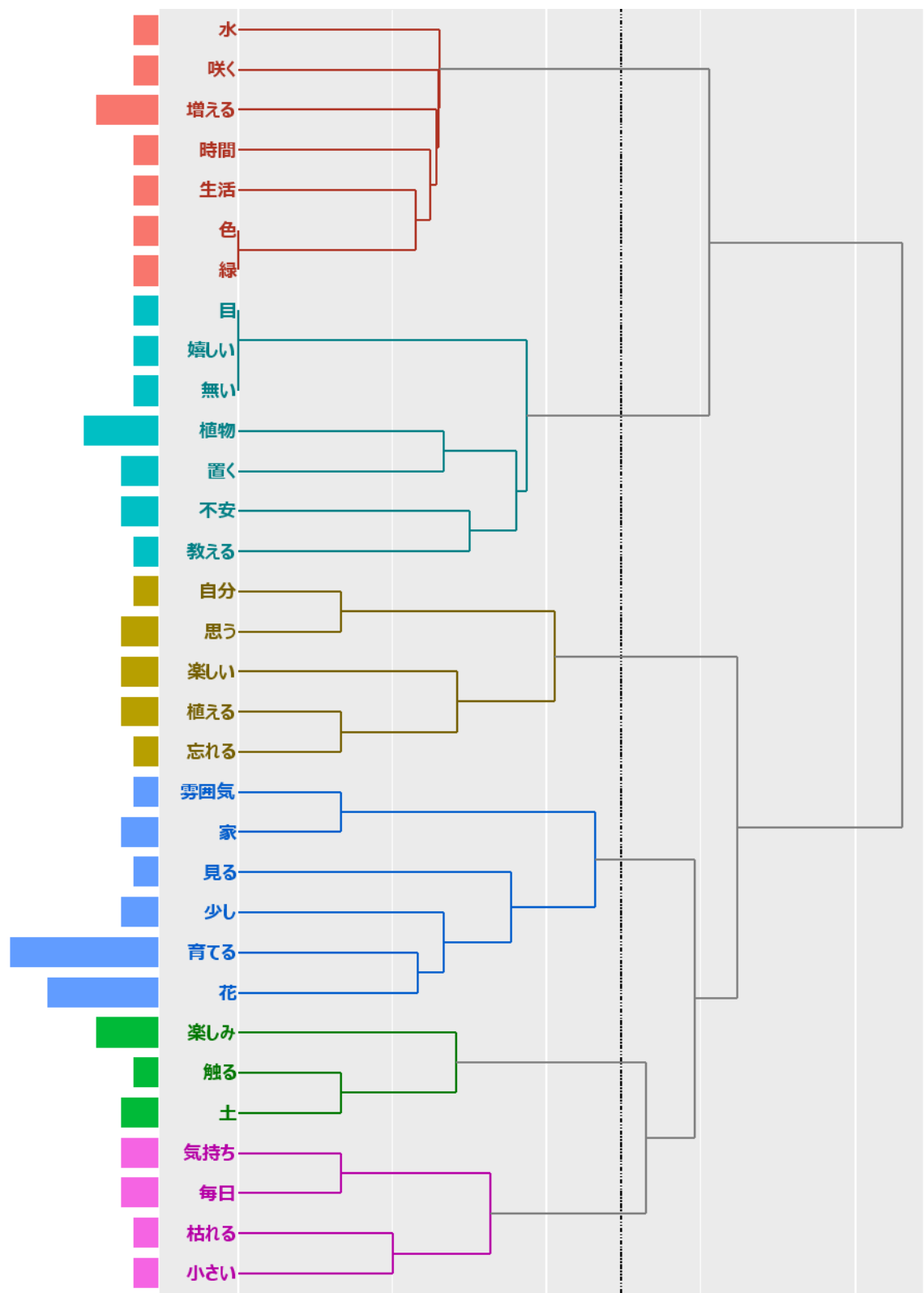

Figure 1. A stratified cluster analysis of before the activity. 


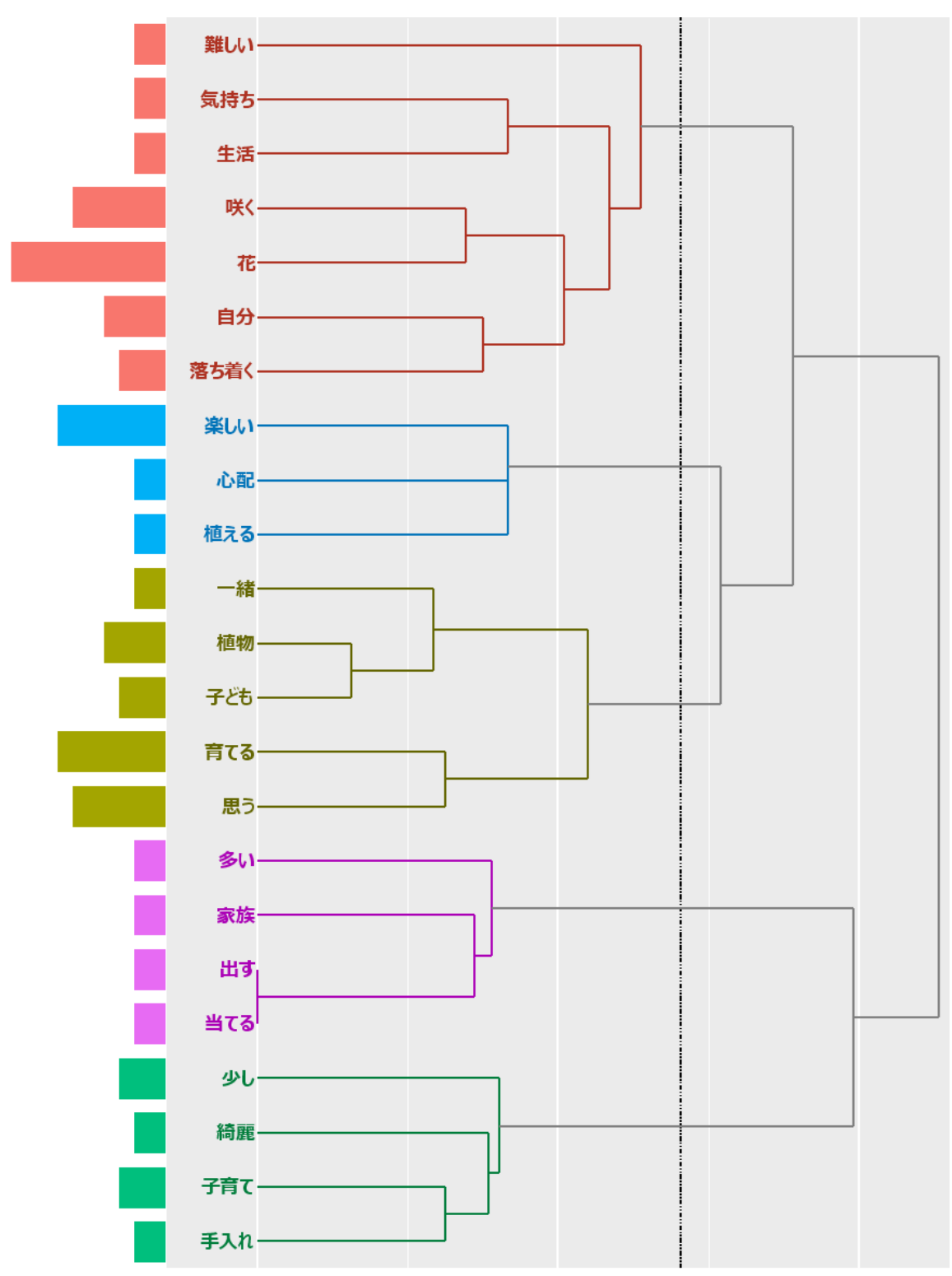

Figure 2. A stratified cluster analysis of the description after the activity.

"bloom", "water", "time", "color", and "green", which can be summarized as related to the horticultural activity itself. Similarly, the word connections extracted for each group revealed that the second and third groups could be grouped into "feelings of touching the soil" and "visual experience of plants". The co-occurrence network diagram of the post-activity descriptions is shown in Figure 4. The co-occurrence network diagram after the horticultural activity shows four subgraphs. The first group containing the most frequently occurring extraction words contains the keywords "flower" and "bloom", which can be summarized as "flowers". Similarly, looking at the connections between the words extracted for each group, it was found that the second group can be summarized as "an emotional experience through plants". Other groupings were "parenting" and "visual experience of plants". 

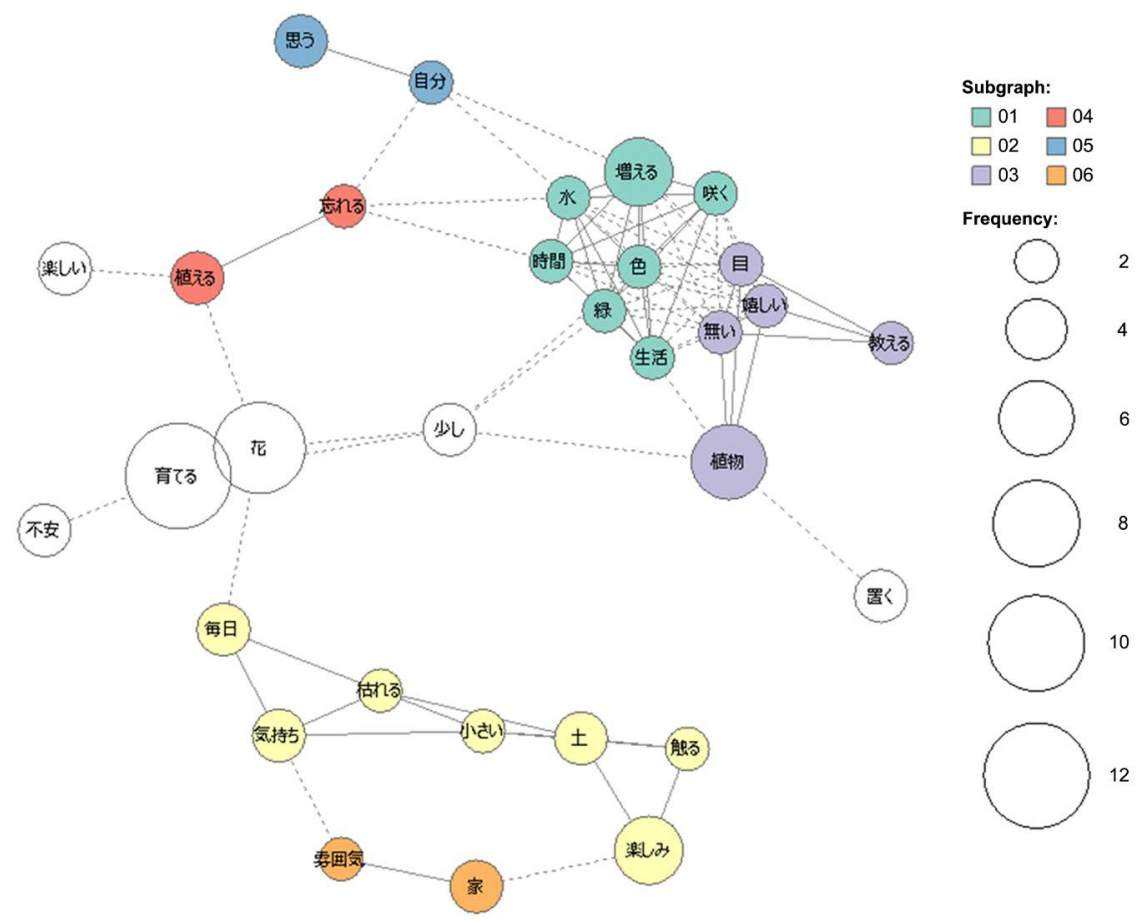

Figure 3. Co-occurrence network of before the activity.

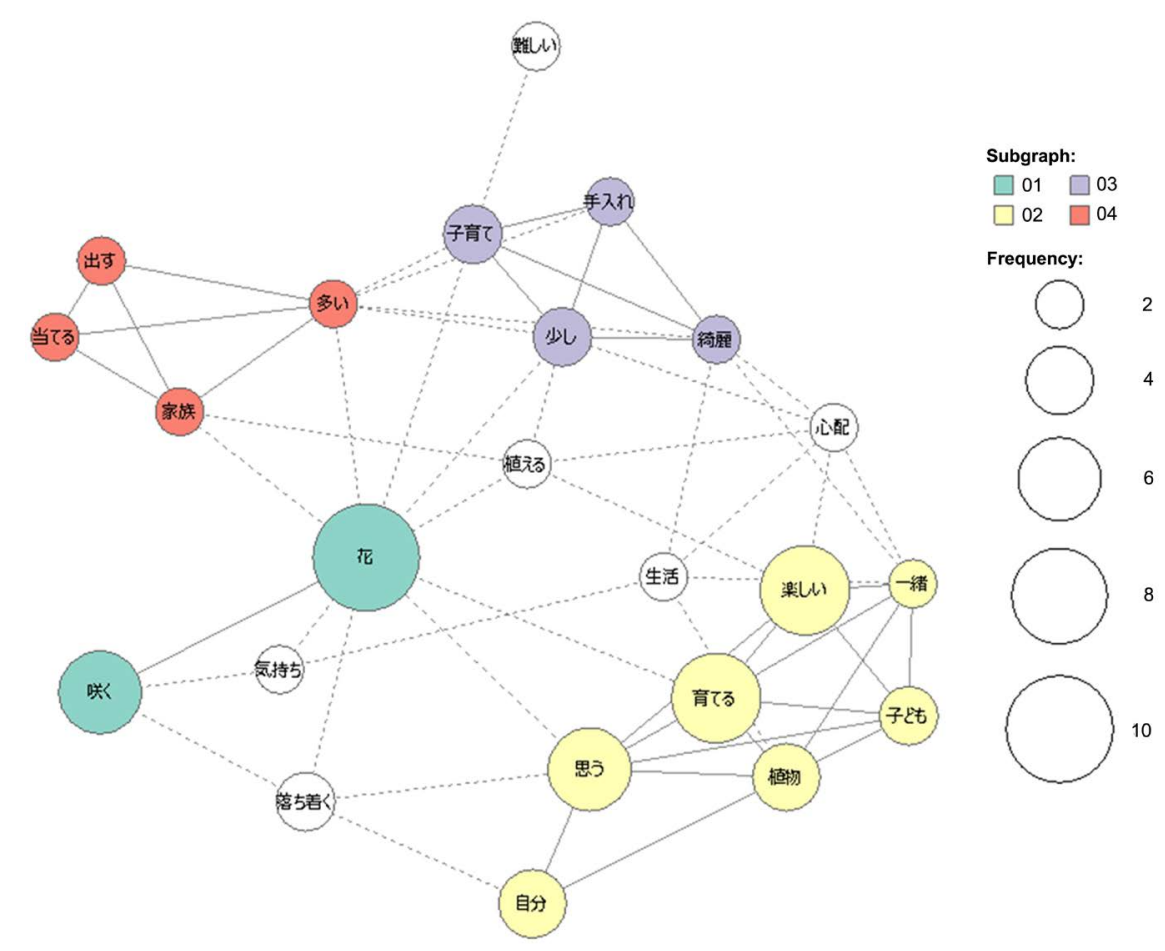

Figure 4. Co-occurrence network after the activity.

\section{Discussion}

This study was an exploratory study using text mining to examine how postpartum women's moods changed before and after engaging in the horticultural activity. Consequently, before the start of gardening activity, phrases related to the 
plants themselves were heavily used, but after the horticultural activity, phrases related to the positive emotional experience through the plants were increasingly used.

In the present study, the most frequent word that frequently appeared before horticultural activities was "growing" (12 times), and it was clear that they had an image of growing plants. The next most frequently occurring words were "flower" (8 times) and "plant" (6 times), which were common nouns for plants. On the other hand, the word that appeared most frequently after horticultural activities was "flower" (10 times), which was a common noun that indicated familiarity with flowers and the next most common words that appeared were "growing" and "fun" (7 times), indicating active involvement and emotional experience. There has been no study of the extraction of emotional experiences using text mining for horticultural activity. As a close area of study, Koga and Iwasaki examine the healing effects of greenery using text mining (Koga \& Iwasaki, 2018). In their study, they asked to write freely about their green usage patterns and their emotional experiences, and text mining was used to extract frequent words. As a result, the most frequent word was "flower", followed by "looking", and most respondents were familiar with flowers and had many visual experiences with plants (Koga \& Iwasaki, 2018). In the case of our study participants, they had no daily gardening experience, and the words that came up before they started horticultural activity were words to describe "growing" and the plants themselves. By engaging in horticultural activity, not only words related to plants such as "flower" and "growing" and "bloom" but also words such as "fun" and "think" were increased in number, indicating that positive emotions were increased by horticultural activity.

Regarding the co-occurrence network of the present study, before the horticultural activity, the groupings were "horticultural activity itself", "feeling of touching the soil", and "visual experience of plants". Free descriptions also indicated that before horticultural activities, "It's good to have more greenery in my life" and "I try my best to water the plants". The statements "I enjoy touching the soil" and "touching the soil makes me feel calm" extracted that touching the soil was healing to them. After the horticultural activity, they were grouped as "flowers", "emotional experience through plants", "parenting", and "visual experience of plants". Slightly different from before the horticultural activity, many felt happy and joyful when the flowers were bloom, as in "it feels good to have flowers in bloom" and "it's fun to see the flowers bloom one after another". They also extracted how they felt about growing flowers and parenting, such as "It's similar to growing flowers and raising children" and "I feel like a child". Also, the verbal cohesion before the horticultural activity did not include emotional words, but after the horticultural activity, a grouping of words such as "fun" and "think" that expressed the emotional experience of being involved with the plants. It has been noted that people develop unique feelings for flowers because they evoke strong positive emotions due to their longstanding associations with food resources (Kellert \& Wilson, 1993). Koga and Iwasaki reported that the 
co-occurrence network extracted not only the remote experience of seeing flowers, but also the experience of healing from active involvement in the flowers, such as growing and decorating them (Koga \& Iwasaki, 2018). Also, Joe suggested that gardening and parenting have a lot in common, and it is that growing them brings out their strength, which leads to a rich harvest (Joe, 2016). Presumably, the participants in this study, in engaging in a horticultural activity they had never done before, were able to juxtapose the daily growth of the plants with the daily growth of their infant, and also felt a sense of accomplishment as the growing of the plants gave them confidence and the flowers they grew bloomed.

There are limitations to this study. As this study was an exploratory pilot study, the sample size was not set. Therefore, a sufficient sample size needs to be investigated in the future.

In conclusion, the present study asked postpartum women to respond in an open-ended format about how the horticultural activity made them feel and used text mining to extract their feelings. Participants frequently used phrases related to the plants themselves with the plants before they began horticultural activity. After the horticultural activity, phrases related to visual experiences and active involvement with plants were more frequent. For mothers who have just had an infant and find it difficult to get away from home, horticultural activities that can be done at home can enhance and maintain a positive attitude. In the future, it needs to be examined with a larger sample because the sample size was not set in this study.

\section{Acknowledgements}

The author appreciates women who participated in the study, and deeply thank Mrs. Teruko Tachibana, Mrs. Yoshiko Sasaki, and Mr. Shuto Kotozaki for study assistant and Oscar Reggie M.D. as study support.

\section{Authors' Contributions}

YK designed the study, conducted the interviews, analyzed the data, and wrote the manuscript. The author read and approved the final manuscript.

\section{Funding}

This work was supported by the grants from Scholarship Fund for Women Researchers in Japan. The funders had no role in study design, data collection and analysis, decision to publish, or preparation of the manuscript.

\section{Availability of Data and Materials}

The datasets analyzed during the current study are available from the corresponding author on reasonable request.

\section{Conflicts of Interest}

The author declares that they have no competing interests. 


\section{References}

Bilszta, J., Ericksen, J., Buist, A., \& Milgrom, J. (2010). Women's Experience of Postnatal Depression-Beliefs and Attitudes as Barriers to Care. Australian Journal of Advanced Nursing, 27, 44-54.

Brennan, P. A., Hammen, C., Andersen, M. J., Bor, W., Najman, J. M., \& Williams, G. M. (2000). Chronicity, Severity, and Timing of Maternal Depressive Symptoms: Relationships with Child Outcomes at Age 5. Developmental Psychology, 36, 759-766. https://doi.org/10.1037/0012-1649.36.6.759

Cimprich, B. (1993). Development of an Intervention to Restore Attention in Cancer Patients. Cancer Nursing, 16, 83-92. https://doi.org/10.1097/00002820-199304000-00001

Cimprich, B., \& Ronis, D. L. (2003). An Environmental Intervention to Restore Attention in Women with Newly Diagnosed Breast Cancer. Cancer Nursing, 26, 284-292. https://doi.org/10.1097/00002820-200308000-00005

Dunkel Schetter, C., \& Tanner, L. (2012). Anxiety, Depression and Stress in Pregnancy: Implications for Mothers, Children, Research, and Practice. Current Opinion in Psychiatry, 25, 141-148. https://doi.org/10.1097/YCO.0b013e3283503680

Evans, J., Heron, J., Francomb, H., Oke, S., \& Golding, J. (2001). Cohort Study of Depressed Mood during Pregnancy and after Childbirth. British Medical Journal, 323, 257-260. https://doi.org/10.1136/bmj.323.7307.257

Friedman, S. H. (2015). Postpartum Psychosis. In Wiley Encyclopedia of Forensic Science (pp. 1-6). Hoboken, NJ: Wiley. https://doi.org/10.1002/9780470061589.fsa294.pub3

Gavin, N., Gaynes, B., Lohr, K., Meltzer-Brody, S., Gartlehner, G., \& Swinson, T. (2005). Perinatal Depression: A Systematic Review of Prevalence and Incidence. Obstetrics and Gynecology, 106, 1071-1083. https://doi.org/10.1097/01.AOG.0000183597.31630.db

Gonzalez, M. T., Hartig, T., Patil, G. G., Martinsen, E. W., \& Kirkevold, M. (2010). Therapeutic Horticulture in Clinical Depression: A Prospective Study of Active Components. Journal of Advanced Nursing, 66, 2002-2013. https://doi.org/10.1111/j.1365-2648.2010.05383.x

Haller, R., Kennedy, K., \& Capra, C. (2019). The Profession and Practice of Horticultural Therapy. Boca Raton, FL: CRC Press. https://doi.org/10.1201/9781315143101

Hansen-Ketchum, P., Marck, P., \& Reutter, L. (2009). Engaging with Nature to Promote Health: New Directions for Nursing Research. Journal of Advanced Nursing, 65, 1527-1538. https://doi.org/10.1111/j.1365-2648.2009.04989.x

Hayashi, N., Wada, T., Hirai, H., Miyake, T., Matsuura, Y., Shimizu, N., Kurooka, H., \& Horiuchi, S. (2008). The Effects of Horticultural Activity in a Community Garden on Mood Changes. Environment Control in Biology, 46, 233-240.

https://doi.org/10.2525/ecb.46.233

Horowitz, J. A., \& Goodman, J. H. (2005). Identifying and Treating Postpartum Depression. Journal of Obstetric, Gynecologic, \& Neonatal Nursing, 34, 264-273. https://doi.org/10.1177/0884217505274583

Joe, L. L. (2016). Gardening \& Parenting_Passions Similar in Many Ways.

Kam, M., \& Siu, A. (2010). Evaluation of a Horticultural Activity Programme for Persons with Psychiatric Illness. Hong Kong Journal of Occupational Therapy, 20, 80-86. https://doi.org/10.1016/S1569-18611170007-9

Kellert, S. R., \& Wilson, E. O. (1993). The Biophilia Hypothesis. Washington DC: Island Press.

Kim, B., Parl, S., Song, J., \& Son, K. (2012). Horticultural Therapy Program for the Im- 
provement of Attention and Sociality in Children with Intellectual Disabilities. HortTechnology Hortte, 22, 320-324. https://doi.org/10.21273/HORTTECH.22.3.320

Koga, Y., \& Iwasaki, Y. (2018). Exploring Emotional Experiences of the Healing Effects of Greenery: A Text Mining Analysis. Environmental Information Science Academic Research Papers, 32, 269-274.

Kozhimannil, K. B., Adams, A., Soumerai, S., Busch, A., \& Huskamp, H. A. (2011). New Jersey's Efforts to Improve Postpartum Depression Care Did Not Change Treatment Patterns for Women on Medicaid. Health Affairs, 30, 293-301. https://doi.org/10.1377/hlthaff.2009.1075

Kumar, R., \& Robson, K. M. (1984). A Prospective Study of Emotional Disorders in Childbearing Women. The British Journal of Psychiatry, 144, 35-47.

https://doi.org/10.1192/bjp.144.1.35

Lang, A. J., Rodgers, C. S., \& Lebeck, M. M. (2006). Associations between Maternal Child Hood Maltreatment and Psychopathology and Aggression during Pregnancy and Postpartum. Child Abuse \& Neglect, 30, 17-25.

https://doi.org/10.1016/j.chiabu.2005.07.006

Maller, C., Townsend, M., Pryor, A., Brown, P., \& Leger, L. S. (2006). Healthy Nature Healthy People: "Contact with Nature" as an Upstream Health Promotion Intervention for Populations. Health Promotion International, 21, 45-54.

https://doi.org/10.1093/heapro/dai032

O’Hara, M. W., \& Swain, A. M. (1996). Rates and Risk of Postpartum Depression-A Meta-Analysis. International Review of Psychiatry, 8, 37-54. https://doi.org/10.3109/09540269609037816

Page, M. (2008). Gardening as a Therapeutic Intervention in Mental Health. Nursing Times, 104, 28-30.

Park, S.-A., Lee, A. Y., Park, H.-G., \& Lee, W.-L. (2019). Benefits of Gardening Activities for Cognitive Function According to Measurement of Brain Nerve Growth Factor Levels. International Journal of Environmental Research and Public Health, 16, 760. https://doi.org/10.3390/ijerph16050760

Pitt, B. (1968). “Atypical” Depression Following Childbirth. The British Journal of Psychiatry: The Journal of Mental Science, 114, 1325-1335. https://doi.org/10.1192/bjp.114.516.1325

Rappe, E. (2005). The Influence of a Green Environment and Horticultural Activities on the Subjective Well-Being of the Elderly Living in Long-Term Care.

Relf, D., \& Dorn, S. (1995). Horticulture: Meeting the Needs of Special Populations. HortTechnology, 5, 94-103. https://doi.org/10.21273/HORTTECH.5.2.94

Rowan, P. J., Duckett, S. A., \& Wang, J. E. (2015). State Mandates Regarding Postpartum Depression. Psychiatric Services, 66, 324-328.

https://doi.org/10.1176/appi.ps.201300505

Sempik, J., Aldridgem, J., \& Becker, S. (2003). Social and Therapeutic Horticulture: Evidence and Messages from Research. Leicestershire: Centre for Child and Family Research, Loughborough University.

Simhi, M., Sarid, O., \& Cwikel, J. (2019). Preferences for Mental Health Treatment for Post-Partum Depression among New Mothers. Israel Journal of Health Policy Research, 8, 84. https://doi.org/10.1186/s13584-019-0354-0

Simon, P., \& Straus, C. (1998). Horticulture as Therapy: Principle and Practice. Philadelphia, PA: Haworth Press.

Ulrich, R. S., Simonst, R. F., Lositot, B. D., Fioritot, E., Milest, M. A., \& Zelsont, M. 
(1991). Stress Recovery during Exposure to Natural and Urban Environments.

Zaers, S., Waschke, M., \& Ehlert, U. (2008). Depressive Symptoms and Symptoms of Post-Traumatic Stress Disorder in Women after Childbirth. Journal of Psychosomatic Obstetrics and Gynecology, 29, 61-71. https://doi.org/10.1080/01674820701804324

Zinga, D., Phillips, S. D., \& Born, L. (2005). Postpartum Depression: We Know the Risks, Can It Be Prevented? Brazilian Journal of Psychiatry, 27, s56-s64.

https://doi.org/10.1590/S1516-44462005000600005 